\title{
American Indian Studies, Multiculturalism, and the Academic Library
}

\section{David L. Alexander}

The current status of multicultural and diversity efforts suggests the need for incorporating into the discussion of librarianship an understanding of previously underrepresented populations such as the American Indian. American Indian Studies speaks from the American Indian perspective and addresses the contemporary condition of American Indians. This article discusses the nature of American Indian Studies and provides suggestions for what librarians can do to support American Indian Studies programs and American Indian students. This example illustrates the importance of acknowledging the validity of diverse worldviews.

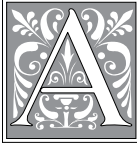

cademic libraries at institutions that have one of the roughly 100 American Indian Studies (AIS) programs in the United States have the opportunity to contribute toward more inclusive campuses by building collaborative partnerships with the AIS programs. ${ }^{1}$ The opportunity exists because the promise of academic libraries providing diverse peoples equal services has not been fully met. AIS programs represent an area of study that deals with American Indian themes while purposefully trying to improve the contemporary condition of American Indians. To build a collaborative partnership with AIS programs, librarians need to learn more about the nature of AIS. Doing so will help the library serve the AIS programs better while at the same time serving American Indian students better.
The collaboration can help strengthen the AIS programs while at the same time helping move campuses forward in terms of fulfilling their goals for multiculturalism and diversity.

\section{Multiculturalism and the Academic Library}

The idea that libraries can serve all users equally well is based on the assumption that libraries are a neutral tool that will be experienced the same regardless of the user. $^{2}$ The reality is that all library users are not equal. Students vary in terms of high school preparation, financial support, stress, and alienation to the campus climate. Students from cultural backgrounds outside the dominant cultural background also differ from those students from within the dominant cultural background in language, perspective, and interests. ${ }^{3}$ A student's worldview

David L. Alexander is Digital Access Manager in University Libraries at The University of South Dakota; e-mail: david.alexander@usd.edu. (C) 2013 David L. Alexander, Attribution-NonCommercial (http:// creativecommons.org/licenses/by-nc/3.0/) CC BY-NC 
helps shape how students interact with libraries, and students of color typically have a worldview that differs from that of students from the dominant cultural group. In addition, a student's previous experiences with racism and oppression may cause students to view institutions such as a large academic library with suspicion. ${ }^{4}$

Diversity efforts in academic libraries address the pluralistic nature of American society and are specifically concerned with how to build an environment that is more inclusive and engaging for people from minority populations. ${ }^{5}$ Academic libraries' efforts toward greater diversity are part of wider university efforts that also acknowledge the importance of creating a diverse learning environment for the benefit it brings to learning. ${ }^{6}$ The ultimate goal for academic libraries with respect to diversity is to "create an environment in which all students and staff are valued, and where full participation and partnership are the norm. ${ }^{\prime 7}$ Toward this end, "education should be concerned with helping people broaden their horizons, value the ideas of others, see and appreciate the variety in humans around the world, and develop their moral and ethical sensibilities, including a sense of justice." ${ }^{8}$

The acknowledgement of the need for higher education institutions to become more inclusive dates back to the postwar social contract between the government and underrepresented groups intended to broaden access to public services. The G. I. Bill, the Economic Opportunity Act of 1964, and the 1965 Higher Education Act are examples of legislation related to the social contract. The National Science Foundation, the National Institute of Health, and the Department of Education all implemented programs intended to improve the status of America's minorities. ${ }^{9}$ The social movements of the 1960s further questioned the privileged position of the white middle-class male. On campuses across the nation, student activism mirrored the social protests and led to a response by colleges and universities. The response came in the form of "aggressively recruiting diverse students and faculty, broadening the curriculum, and opening avenues for new areas of research and scholarship." ${ }^{10}$ College and university libraries responded by hiring more minority staff and broadening and strengthening collections to address programmatic changes in areas of race, ethnic, and gender studies.

Increasing recruitment was an important first step in support of diversity in the academy. Nevertheless, increasing recruitment is not enough to correct underrepresentation because it does nothing to address the barriers that contributed to underrepresentation in the first place. Denise Adkins and Lisa Hussey explained, "Libraries share a perception of embracing and providing for all users. However, they also share a common philosophical stance shaped by librarians' individual discursive formations and the dominant cultural hegemony that values some users over others."11

One factor that led to underrepresentation was a difference in power between the dominant and minority groups. Library collections built around the scholarship of the dominant cultural group inherently devalued the intellectual accomplishments of other cultural groups. Library epistemology that developed out of the Western tradition similarly has a limiting influence on cultural diversity and recruitment practices within academic libraries. ${ }^{12}$

A variety of programs have been initiated in higher education and academic libraries that address the disadvantages faced by minorities in the higher education system. These programs include support services for students from minority groups, various professional development programs for minority staff, and cultural awareness training at both student and staff levels intended to develop better understanding of the minority experience. While progress has clearly been made over the last half century in terms 
of diversity and multicultural awareness, there is also a general sense that more needs to be done to make the academy truly inclusive for all the minority groups found in the pluralistic American society.

Academic libraries' efforts toward greater diversity are part of wider university efforts that acknowledge the importance of creating a diverse learning environment for the benefit it brings to education. ${ }^{13}$ The American Research Libraries' (ARL) diversity initiatives have been focused on moving toward a library workforce that more closely matches the proportions of minorities in American society represented by the Leadership and Career Development Program (1997), the ARL Initiative to Recruit a Diverse Workforce (1999), the Career Enhancement Program for Minority MLS Students (2008), and the Leadership Institute for MLS Students. ARL also partnered with OCLC in offering the OCLC Minority Librarian Fellowship Program.

If libraries are to further advance diversity and multiculturalism, a "next generation agenda" needs to be pursued. The definition of librarianship needs to be expanded to include issues such as the international and intercultural aspects of scholarly communication, reducing barriers that affect collections, research, topics, human resources, and other aspects, and addresses the connection between learning style differences and diverse populations. $^{14}$

An additional step that academic libraries can take to become more inclusive organizations is to acknowledge the validity of diverse perspectives and worldviews. Toward that end, library literature needs to include the discussion of the nature of disciplines such as AIS that inherently relate to libraries serving what have historically been underserved peoples.

\section{American Indian Studies}

The American Indian became an object of study with the development of the social sciences. But it was not until the social movements of the 1960s led to changes on college campuses that AIS programs appeared. ${ }^{15}$ From the beginning, AIS programs had the basic commitment "to attempt, through education and research, to effect some social change in the lives of Native American people." 16 Change will come from "research conducted within a theoretical framework that attempts to place Native American communities within the overall context of American society and to determine how the structures and values of contemporary Native American communities are affected by the larger American society within which those communities exist."17

The popular image of American Indians is one area that impacts how American Indians are treated in the larger society. The popular image was created largely by distorted or stereotypical images based on a romanticized vision of the past. The result is that there is little connection between the popular images of American Indians and the realities of contemporary American Indian life. "It is as if the hopes of nineteenth century assimilationists for a 'vanishing red man' had been realized psychologically in the public's mind." 18

The lack of accurate information on American Indians was and continues to be also reflected in academics and academic libraries. Elizabeth Katz and Celeste West edited a 1972 volume titled Revolting Librarians that specifically addressed the issue of what the library establishment was not speaking about. Of particular interest is Joan Marshall's argument that

If librarians defend their rights as educators to present all points of view in their collections . . . they must accept their obligation to provide an approach to their collections that is equally without bias, one which does not reinforce psychological, sociological, economic, political, and other assumptions and prejudices of their public. ${ }^{19}$ 
Sanford Berman's article in the same volume addressed the lack of diversity in library collections and descried the racist, sexist, and ageist subject headings. ${ }^{20}$ The subject headings have since been revised with improvements, but there may still be inherent biases in the classification schemes that work against minority groups.

Consider the example of the American Indian. The reality is that the vast majority of materials in libraries on American Indians were written from the exogenous perspective. Any classification scheme developed based on existing conditions in libraries will naturally reflect observable categories in the materials written from the exogenous perspective. AIS, however, specifically studies American Indians from a perspective that originates inside Indian cultures. This perspective leads to the endogenous consideration of American Indians and is a sharp contrast to the exogenous consideration from which other disciplines had viewed and often continue to view Indian affairs. ${ }^{21}$

The endogenous perspective views American Indian affairs more from the tribal perspective as opposed to an exogenous perspective that considers Indian affairs in terms of their relationship to the dominant mainstream perspective. Both endogenous and exogenous considerations are insightful, but for different purposes, and both are legitimate approaches to studying phenomena. ${ }^{22}$ However, it is the endogenous perspective that separates AIS from more traditional academic disciplines such as history, religion, politics, sociology, and ethnology.

History is an example that illustrates the difference between endogenous and exogenous perspectives. An exogenous consideration may speak of Indian history in relation to the expansion of the United States. An endogenous consideration, on the other hand, would speak of Indian histories that reflect various tribes' experiences dealing with the expansion of the United States.
It is important to note that the view of Indians as a group is an exogenous perspective that developed with the colonization of the Americas. American Indians tend to identify themselves at the tribal level or at the extended family level. AIS typically focuses on the tribal level unless dealing with a topic that is specifically pan-Indian. For example, the Native Studies curriculum at The University of South Dakota were developed around the concept of the Oceti Sakowin Oyate, an endogenous description of the tribes that made up what the exogenous perspective labeled the Sioux tribes.

Another layer of complexity related to worldviews is that cultural context can lead to different interpretation or assignment of meaning. History again serves as an example. Colonization is often taught as something that occurred in the past that led to the advancement of American civilization. But for American Indian peoples, colonization represents loss of tribal homelands and loss of control over their affairs. The legacy of colonization continues to have an impact on their daily life because colonial (nonnative) structures still exist in contemporary American society.

American Indians may perceive history with more immediacy as a result of the near genocide conducted against the American Indian. Because there were only about 250,000 Indians remaining in 1900, there is a high degree of likelihood that contemporary American Indians can trace a relatively direct link to Indian historical figures in a way that white Americans can only do in rare circumstances. ${ }^{23}$

One cannot begin to understand contemporary American Indian life without understanding the treatment of the American Indian in American history. "At the same time, the present reality of Indian community life must be defined in relationship to the continuity of identity from historical past to the present and also to the changes in identity that have taken place through assimilation and acculturation of native communities to the dominant society." 24 
Colonialism, as it represents the loss of American Indian control over American Indian affairs, is a theme that underlies virtually every area of AIS, every area of contemporary American Indian life, and the history of American Indian relations for the last 500-plus years. Consideration of colonialism as a context also speaks to the problem Indians have presented to the expansion of Western empires.

Some other important terms related to colonization and American Indian tribes are sovereignty, self-determination, and revitalization. Despite being legally sovereign nations, tribes enjoy limited sovereignty and tribal governments remain dependent on the United States. ${ }^{25}$ Selfdetermination refers to tribes regaining control over their own affairs. In Indian education this concept is closely associated with the tribal college movement. ${ }^{26}$ Revitalization refers both to increasing population among American Indian tribes and to a return to or strengthening of indigenous values among contemporary American Indian peoples.

American Indian Studies as a discipline attempts to establish unique intellectual areas of consideration. For example, oral traditions, undervalued in Western history, have validity as an area of study with respect to American Indian tribal histories. Other areas of study include treaty rights, tribal government (traditional and contemporary), social organization (traditional and contemporary), American Indian epistemology, contemporary American Indian issues, American Indian education, American Indian ecology, and so on.

\section{Supporting American Indian Studies Programs}

The discipline of American Indian Studies is relatively small and has been slow to develop even in comparison to programs such as ethnic studies, gender studies, or area studies that started around the same time. In the beginning, the number of potential Indian Studies faculty members was limited by the small number of Indian students that had made it into college and the even smaller number that completed their higher education. ${ }^{27}$ In the early days of AIS, the faculty were expected to perform administrative functions, develop the curriculum, recruit American Indian students, and provide American Indian student support services. The variety of duties limited the time faculty gave to research and, as a result, hampered the production of a significant body of published scholarship. ${ }^{28}$ The situation has improved over time, and outside bodies now often handle recruitment and student support services, but AIS faculty are still often pulled in multiple directions. This continues to hamper the development of the discipline.

The first thing that librarians should know about AIS programs is that, with the slow development, there is a great deal of variation between AIS programs. Some programs are housed in other departments and remain interdisciplinary in structure. In such a case, control over the hiring of faculty and curriculum lies with the department housing the program. The significance of an AIS program achieving departmental status is that it is freed from its dependence on outside departments to provide teachers for interdisciplinary courses that contribute to the AIS program. With department status, an AIS program controls the hiring of faculty and can look for those that have American Indian Studies as their primary focus. With stronger AIS backgrounds, those faculty members can in turn help develop courses with a stronger AIS focus.

Whether an AIS program is a department or housed elsewhere,

the program still generally draws on the expertise of people who have been trained in various established disciplines, usually history or anthropology. But the rhetoric of the Indian students and community leaders who have requested or demanded the establishment of programs has often stressed that the 
past research that has been done and the approaches of the established disciplines have been irrevocably biased. ${ }^{29}$

AIS directly deals with the scholarship about American Indians that developed out of the Euro-American, white cultural tradition that Ward Churchill described as educational imperialism..$^{30}$ It is ironic that, to be a legitimate academic program in American higher education institutions, AIS "must conform to sets of conceptual standards which are patently in opposition to Native American realities and which are allegedly its raison d'etre." ${ }^{\prime 11}$ But, as long as AIS exists within mainstream educational institutions, tension will exist between the system and the field of study that inherently questions the validity of the system.

An aspect of American Indian Studies research is that it has yet to develop a distinct set of methodological procedures, techniques, or apparatus. It uses various means of collecting and analyzing data and other information, from a variety of other disciplines. ${ }^{32}$ At the same time, American Indian Studies questions whether or not externally developed methodologies are adequate to explain the unique experiences of American Indian peoples.

In terms of collection development, academic librarians should be aware of the limitations of the traditional academic press system with respect to providing quality materials for American Indian Studies. Because American Indian Studies is an emerging discipline, the mainstream academic presses may not provide sufficient coverage. University presses such as The University of Nebraska Press, The University of Oklahoma Press, and The University of Arizona Press have an established record publishing scholarship related to American Indians and are good sources for books in this field. Librarians may also want to watch smaller regional presses for relevant materials that have not made it into mainstream academic presses. Librarians should keep in mind that American Indian Studies continues to share methodologies with other disciplines and that American Indian-related scholarship produced in other disciplines still has relevance for American Indian Studies. If funds for supporting American Indian Studies are limited, other academic departments might be called upon for purchasing books about American Indians that overlap with other areas of study.

In terms of scholarly articles, the AIS discipline is fairly small. Scholarly journals in the discipline include Wicazo $S a$ Review, American Indian Quarterly, American Indian Culture and Research Journal, and Sail (formerly Studies in American Indian Literature). Scholarly journals from other disciplines may include articles about American Indians, but they are less likely to be written from the American Indian perspective. ${ }^{33}$

To properly support American Indian Studies programs, it is necessary for academic librarians to have an understanding of the nature of American Indian Studies programs. Collection development policies for American Indian Studies should reflect a tribal focus and use pan-Indian materials to support relevant topic areas.

One of the central topics of study in American Indian Studies is the American Indian response to colonization. This topic might be explored at the level of an individual tribe, but it might equally be a comparison between the experiences of multiple tribes or from the viewpoint of the colonizer. Colonization is also an area in which American Indians can compare their experience with indigenous peoples from any part of the world.

\section{Supporting American Indian Students}

Librarians need to be aware that there is also variation among individuals within a cultural group. American Indian students are not all the same. Students vary in geographic background. Some come from rural reservations, while others hail from cities. Some students have more of 
a traditional American Indian cultural orientation than others. Some want to identify as American Indian and participate in cultural activities; others do not. Some students may have graduated from a school that did not adequately prepare them for college, while other students may have graduated from a school that prepared them well.

Personal or family history may work against some American Indian students with respect to attending a higher education institution and using the library. Indian culture was believed to detract from the chance the Indian student would successfully complete his or her education. Decades of educational policy sought to separate American Indian students from their cultural heritage. ${ }^{34}$ Research, primarily conducted since the 1960s, has shown that knowledge of tribal culture is actually beneficial and helps give American Indian students a positive self-identity that supports them in their pursuit of education. But there is still a legacy of schools prohibiting cultural practices, including the speaking of Native languages, of removing American Indian children from their homes to boarding schools, of abuse in boarding schools, and so on that may impact some American Indian students' experience with education. There is a connection to many of the social problems faced in Indian communities today to the educational policies of the past. Librarians working with American Indian students should at least be aware that distinct historical context and student backgrounds may complicate American Indian students' educational experience, but the librarians should not assume that is true of all American Indian students. Librarians should acknowledge the value of cultural activities and student services that support American Indian students. Librarians should take advantage of opportunities to learn more about American Indian history, culture, and contemporary society when those opportunities are available.
Librarians who want to support American Indian students more actively can investigate what support programs are available and ask to be involved. For example, a library tour could be offered if the college or university has a separate orientation program for American Indian students. A representative from the library could also attend any type of welcome or support activity held for American Indian students throughout the year. Librarians can also take library services to the American Indian students. If there is some type of American Indian center where students gather, a librarian can hold office hours there. Librarians who get to know American Indian students through these types of activities will make the library and librarians more approachable when it comes time for the students to use the library and make the students more likely to seek help if they need research assistance.

\section{Conclusions}

It is important to keep in mind that AIS is a young discipline that is continuing to develop. The discipline identifies key themes and issues such as those discussed above and provides a framework for analyzing the themes and issues. The research publications from the discipline are still comparatively small in number. Collection development efforts should work to include materials related to the themes and issues of the discipline. This includes looking outside the more traditional academic publishers and looking for the most relevant materials in related disciplines.

American Indian Studies is closely connected to supporting American Indian students. Academic librarians who want to support American Indian students should keep in mind that American Indians are a distinct population within American society. Historical circumstances and cultural characteristics may make the college experience very different for some American Indian students. At the same time, a great deal of variation exists between American 
Indian students. Academic librarians can learn more about American Indians and work to build collaborative partnerships with AIS departments and student services in supporting American Indian students. Two recommended practices toward this goal would be to include the library if there is an orientation to campus specifically for American Indian students and to hold office hours where American Indian students gather such as an American Indian culture center.
The most important point for taking multiculturalism and diversity efforts to the next level is to acknowledge the validity of worldviews inherent in diverse groups such as American Indians. The acknowledgement needs to be reflected in practice. Librarians wanting to make a contribution to multiculturalism and diversity efforts should strive to learn more about diverse peoples and translate this knowledge into collection development policies and services.

\section{Notes}

1. See https://facultystaff.richmond.edu/ rnelson/asail/guide/guide.html for Robert M. Nelson's listing of American Indian studies programs.

2. Thomas Weissinger, "Competing Models of Librarianship: Do Core Values Make a Difference?" The Journal of Academic Librarianship 29, no. 1 (Jan. 2003): 32.

3. Rebecca R. Martin, "Changing the University Climate: Three Libraries Respond to Multicultural Studies," The Journal of Academic Librarianship (Mar. 1994): 2-9.

4. Rhonda Rios Kravity, Adelia Lines, and Vivian Sykes, "Serving the Emerging Majority: Documenting Their Voices," Library Administration \& Management 5 (1991): 184-88.

5. Roberto G. Trujillo and David C. Weber, "Academic Library Responses to Cultural Diversity: A Position Paper for the 1990s," The Journal of Academic Librarianship 17, no. 3 (1991): 157-61.

6. Barbara I. Dewey, "The Imperative for Diversity: ARL's Progress and Role," portal: Libraries and the Academy 9, no. 3 (July, 2009): 355-61.

7. Roberto G. Trujillo and David C. Weber, "Academic Library Responses to Cultural Diversity: A Position Paper for the 1990s," The Journal of Academic Librarianship 17, no. 3 (1991): 157.

8. Trujillo and Weber, "Academic Library Responses to Cultural Diversity," 158.

9. See William C. Welburn's discussion of Nancy Cantor's 2002 speech in "Creating Inclusive Communities: Diversity and the Responses of Academic Libraries," portal: Libraries and the Academy 10 (2010): 355-63.

10. Welburn, "Creating Inclusive Communities," 355.

11. Denise Adkins and Lisa Hussey, "The Library in the Lives of Latino College Students," The Library Quarterly 76 (2006): 457.

12. Ibid.

13. Dewey, "The Imperative for Diversity."

14. Ibid.

15. For a discussion on the origins of American Indian Studies programs, see (for example) M. Annette Jamies, "American Indian Studies: Toward an Indigenous Model," American Indian Culture and Research Journal 11, no. 3 (1987): 1-16.

16. Clara Sue Kidwell, “Native American Studies: Academic Concerns and Community Service," American Indian Culture and Research Journal 2 (1978): 7.

17. Ibid.

18. Terry P. Wilson, “Custer Never Would Have Believed It: Native American Studies in Academia," American Indian Quarterly 5 (1979): 224.

19. Joan Marshall, "LC Cataloging: An Indictment," in Revolting Librarians, ed. Celeste West and Elizabeth Katz (San Francisco, Booklegger Press, 1972), 45-49.

20. Sanford Berman, "Libraries to the People!" in Revolting Librarians, ed. Celeste West and Elizabeth Katz (San Francisco, Booklegger Press, 1972), 51-57.

21. Russell Thornton, "American Indian Studies as an Academic Discipline," American Indian Culture and Research Journal 2, no. 3/4 (1978): 13.

22. Ibid.

23. Population cited in Nancy Bonvillain, Native Nations: Cultures and Histories of Native North America (Prentice Hall: Upper Saddle River, N.J., 2001), 32.

24. Kidwell, “Native American Studies," 6.

25. The situation of American Indian Studies in terms of campus politics is very similar. Ameri- 
can Indian Studies challenges both the popular image of the American Indian and the traditional views of the American Indian developed in various disciplines. At the same time, American Indian Studies is part of the educational system that it critically analyzes. This tension may also serve to slow the development of the discipline.

26. David L. Alexander, The South Dakota Tribal College Experience: Historical Context, Student Background, and Student Perspectives (UMI Dissertation Services, 2007).

27. Vine Deloria, Jr., "Indian Studies: The Orphan of Academia," Wicaza Sa Review 2, no. 2 (1986): 1-7.

28. Wilson, "Custer Never Would Have Believed It."

29. Kidwell, "Native American Studies," 5.

30. Ward Churchill, "National Patterns in Contemporary Indian Studies Programs," Multicultural Education and the American Indian (1979), cited in M. Annette Jamies, "American Indian Studies: Toward An Indigenous Model," American Indian Culture and Research Journal 11, no. 3 (1987): 1-16.

31. M. Annette Jamies, "American Indian Studies," 7.

32. Thornton, "American Indian Studies as an Academic Discipline," 13.

33. For additional discussion of publishing related to American Indian Studies, see Daniel F. Littlefield, Jr., "The American Native Press and American Indian Studies," Wicazo Sa Review 2, no. 2 (Autumn 1986): 51-57.

34. See, for example, David L. Alexander, The South Dakota Tribal College Experience: Historical Context, Student Background, and Student Perspectives (UMI Dissertation Services, 2007) for a discussion of the history of Indian education in the United States.

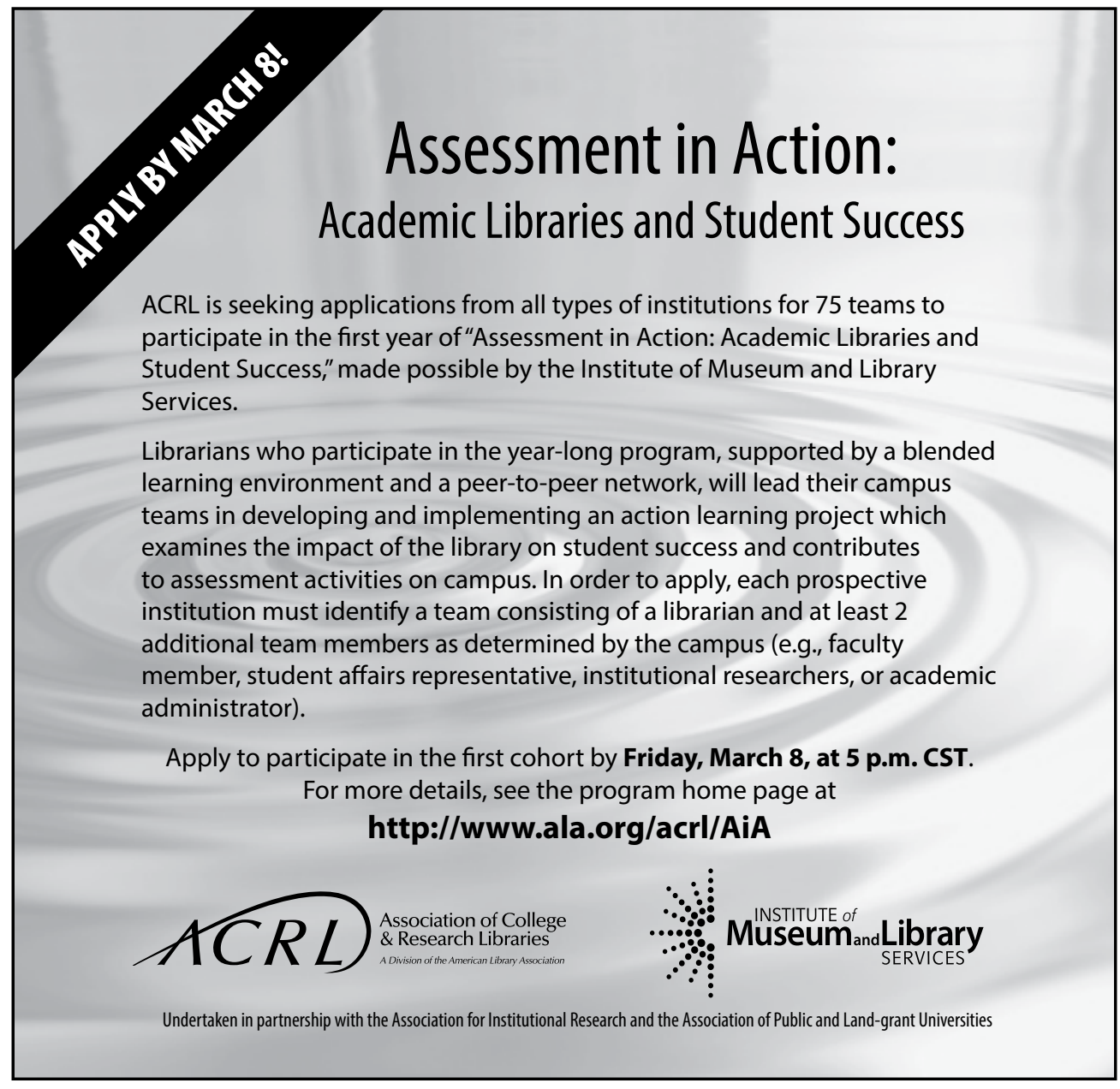

